\title{
Effects of aspartame metabolites on astrocytes and neurons
}

\author{
Karol Rycerz, Jadwiga Elżbieta Jaworska-Adamu \\ Department of Animal Anatomy and Histology, Faculty of Veterinary Medicine, University of Life Sciences, Lublin, Poland
}

\begin{abstract}
Aspartame, a widespread sweetener used in many food products, is considered as a highly hazardous compound. Aspartame was discovered in 1965 and raises a lot of controversy up to date.

Astrocytes are glial cells, the presence and functions of which are closely connected with the central nervous system (CNS). The aim of this article is to demonstrate the direct and indirect role of astrocytes participating in the harmful effects of aspartame metabolites on neurons.

The artificial sweetener is broken down into phenylalanine (50\%), aspartic acid (40\%) and methanol (10\%) during metabolism in the body. The excess of phenylalanine blocks the transport of important amino acids to the brain contributing to reduced levels of dopamine and serotonin. Astrocytes directly affect the transport of this amino acid and also indirectly by modulation of carriers in the endothelium. Aspartic acid at high concentrations is a toxin that causes hyperexcitability of neurons and is also a precursor of other excitatory amino acid - glutamates. Their excess in quantity and lack of astrocytic uptake induces excitotoxicity and leads to the degeneration of astrocytes and neurons.

The methanol metabolites cause CNS depression, vision disorders and other symptoms leading ultimately to metabolic acidosis and coma. Astrocytes do not play a significant role in methanol poisoning due to a permanent consumption of large amounts of aspartame.

Despite intense speculations about the carcinogenicity of aspartame, the latest studies show that its metabolite - diketopiperazine - is cancirogenic in the CNS. It contributes to the formation of tumors in the CNS such as gliomas, medulloblastomas and meningiomas. Glial cells are the main source of tumors, which can be caused inter alia by the sweetener in the brain.

On the one hand the action of astrocytes during aspartame poisoning may be advantageous for neuro-protection while on the other it may intensify the destruction of neurons. The role of the glia in the pathogenesis of many CNS diseases is crucial.
\end{abstract}

Key words: aspartame, aspartate, diketopiperazine, phenyloalanine, receptors, transporters, neurodegeneration.

\section{Introduction}

Aspartame (APM) is an artificial sweetener widespread in the world which is used in many food products like chewing gum, desserts, yoghurts, vitamins, medicines and particularly in diet beverages. It was found that aspartame is present in $68 \%$ of comestible assortment among sugar-free products in Poland [28]. It is applied by diabetics as tablets instead of sugar (NutraSweet, Equal, Sugar Free, Canderel). The sweet- 
ener was accidentally discovered by James Schlatter during his attempts to obtain a gastric ulcer drug in 1965 [9]. This white, crystalline and odourless powder is 180-200 times sweeter than sucrose. The intense sensation of sweetness allows the use of such small doses so that the product is almost non-caloric although its energy value is $4 \mathrm{kcal} / \mathrm{g}$ of aspartame. The sweetener is a chemical agent, $\mathrm{N}$-L-alpha-Aspartyl-L-phenylalanine methyl ester (C14H18N2O5) [26]. This substance is hydrolysed completely to the three main breakdown products: phenylalanine (50\%), aspartic acid (40\%) and methanol (10\%) in the intestinal lumen. The use of aspartame as a sweetening agent has been controversial for years due to the harmful effects of high concentrations of the metabolites. Hence the European Food Safety Authority established an acceptable daily intake of $40 \mathrm{mg} / \mathrm{kg}$ b.w./day [8,17].

Most articles about harmful effects of the artificial sweetener are focused primarily on its negative influence on the nerve cells $[2,3,5,7,19]$. And only in a few studies the effect of aspartame on glial tissue, which inextricably accompanies neurons, has been described $[15,29]$. Therefore, the aim of this article is to show the direct and indirect role of astrocytes which participate in the harmful effects of aspartame metabolites. Among many functions of astrocytes one is to nourish the nerve cells and compose a stroma in the form of neuropil for them. They set up the blood-brain barrier and also regulate the homeostasis of ions $\left(\mathrm{Ca}^{2+}, \mathrm{K}^{+}\right)$, maintain water balance (AQP4 - aquaporin 4), provide substrates for the synthesis of neurotransmitters (particularly glutamate - Glu, $\gamma$-amino butyric acid - GABA, and serotonin - 5-HT) and are involved in their uptake and metabolism [20]. Aspartame interference in these functions may directly or indirectly evoke the development of many adverse symptoms such as headaches, dizziness, seizures, nausea, numbness, muscle spasms, rashes, depression, fatigue, irritability, insomnia, vision problems, hearing loss, heart palpitations, anxiety attacks, slurred speech, tinnitus, memory loss, learning disabilities and joint pain [1]. Astrocytes can presumably take part in positive and negative effects of aspartame metabolites in view of their functions and participation in metabolism of neurons.

\section{Astrocytes influence on the transportation of phenylalanine}

One of the major metabolite of aspartame is phenylalanine (Phe), the sweetener's breakdown product.
This naturally essential amino acid after applied with nutrients to an organism joins the general pool of amino acids present in the blood. It is partly transformed into tyrosine by phenylalanine hydroxylase and then to L-3,4-dihydroxyphenylalanine (DOPA), dopamine (DA), noradrenaline (NA) and adrenaline (A) in the liver. Phenylalanine may be used in protein synthesis and also to convert into phenylpyruvic acid present in high concentration in patients with phenylketonuria (PKU) [21].

The remaining pool of phenylalanine crosses to the brain by neutral amino acid transporters (NAAT) mainly situated in capillary vessels, a part of bloodbrain barrier (BBB). These transporters are used to transport various amino acids: glutamine, histidine, methionine, serine, threonine, tyrosine and tryptophan, which are important for neurotransmitters' synthesis. Astrocytes are involved in the modulation of the blood-brain barrier and thus influence the transport of amino acids by the endothelium. Under the influence of astrocytic factors in the endothelial cell cultures derived from rat's brain using an RT-PCR method, the expression of one of the subunits building amino acid transporters (4F2hc - heavy chain) was shown. These glial cells can modulate transport of inter alia phenylalanine through the wall of the capillaries. $\mathrm{Na}^{+}$-independent (L1 system - transport of large essential neutral amino acids) and $\mathrm{Na}^{+}$-dependent endothelial transporters hold a subunit in the form of 4F2hc heavy chain. This suggests that astrocytes are involved in the uptake of neutral amino acids (NAAs) through functional changes of many NAAT transporters.

Astrocytic end feet reaching the basilemma of the endothelium contain many membrane transporters which participate in the entry of phenylalanine into the CNS. It was shown that the $\mathrm{Na}^{+}$-dependent large neutral amino acid transporters ( $\mathrm{Na}^{+}$-LNAA system) are present in the astrocytes and therefore they may be involved in the penetration of Phe across the bloodbrain barrier. Presumably, astrocytes are directly involved in the transport of phenylalanine and in the increase of its concentration in the brain after consumption of aspartame $[4,14,23]$. All amino acids which can pass through the BBB compete for the transporter. The affinity of the carriers is proportional to the concentration of amino acids in the blood. Higher concentrations of the amino acid in the blood enhance the ability to bind a transporter. Consuming aspartame increases the pool 


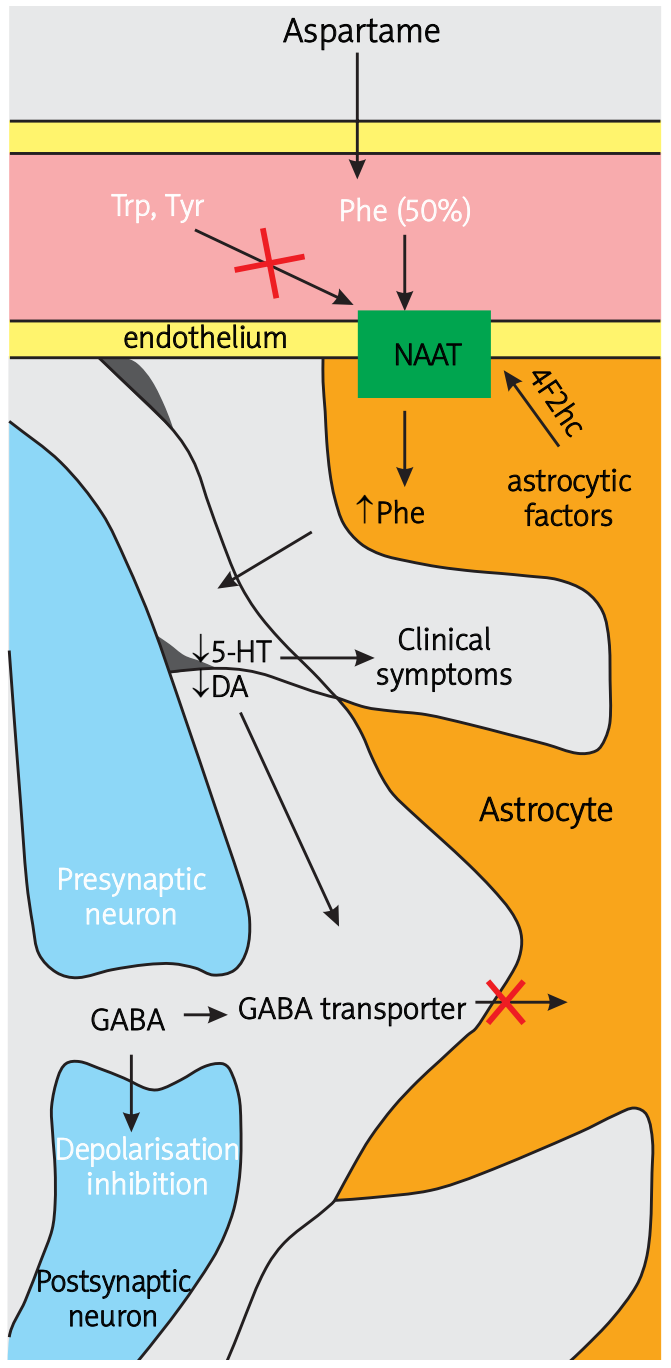

Fig. 1. Aspartame is broken down into phenylalanine (Phe). An excess of Phe in the bloodstream blocks the NAAT transporters preventing important amino acids (Trp, Tyr) from crossing the blood-brain barrier (BBB). Astrocytes possess NAAT transporters and have the ability to modulate carriers with 4F2hc heavy chain subunit in the endothelium. Phe contributes indirectly to lower levels of serotonin (5-HT) and dopamine (DA), which causes clinical symptoms. This leads also to reduced activity of $\gamma$-amino butyric acid (GABA) transporters, which impairs its uptake by astrocytes. GABA inhibits the postsynaptic membrane depolarisation.

of phenylalanine in plasma. It results in binding phenylalanine to the transporters crossing BBB and thus the saturation of NAAT causes that important amino acids necessary for proteins and neurotransmitters synthesis cannot pass to the brain. One of the essential amino acids delivered to the CNS by the BBB is tyrosine (Tyr) required for the synthesis of dopamine (DA) and nonessential amino acid - tryptophan (Trp) involved in the formation of serotonin $(5-\mathrm{HT})$. As a result of lack of neutral amino acid transporters after binding phenylalanine to them, there is a deficiency of other amino acids resulting in decreased production of these two neurotransmitters (Fig. 1). Low dopamine levels in neurons of the substantia nigra in the midbrain forming neural pathways reaching the striatum (globus pallidus, putamen and nucleus caudatus) and brain cortex, lead to a reduction in mobility, balance and walking. These alterations are the first symptoms of Parkinson's disease $[3,15,30]$. In adult mice it was shown that the low concentrations of dopamine in the dopaminergic system also cause disorders in exploratory behaviour, adipsia and aphagia [32].

Lower levels of serotonin in the hippocampus, raphe nucleus of the brain stem and substantia nigra in the midbrain affect sleep, memory, sensory perception, control of mood, temperature regulation disorders, depression and anxiety in adults. The reduction of serotonin levels in the development of CNS can affect cell proliferation, differentiation and migration of neurons and synaptogenesis. Serotonin deficiency in the prenatal period leads to developmental disorders of the respiratory system $[6,11,15]$. Astrocytes may be involved in the above alterations caused by phenylalanine derived from aspartame because they capture, break up, metabolize and exocytose serotonin [10].

Decreased levels of serotonin caused indirectly by phenylalanine lead to GABA transporters activity reduction in astrocytes which in consequence causes an excess quantity of GABA neurotransmitter resulting in continuous depolarisation inhibition of postsynaptic membranes in neurons [15].

In summary, phenylalanine can directly influence the reduction of other important amino acids penetration into the CNS by its competition for NAAT transporters. Consequently, it affects indirectly the deficiency of certain neurotransmitters leading to functional disorders. Astrocytic end feet may be involved in the harmful effects of aspartame on the CNS through modulation of transport properties in the BBB endothelium. Membrane transporters may lead to penetration of this amino acid into the astrocytes and influence their functions. 


\section{Excitotoxicity of aspartate and glutamate in the CNS}

Aspartate, as a nonessential amino acid in brain, acts as a neurotransmitter responsible for transmission of impulses between neurons. Aspartic acid makes up $40 \%$ of the aspartame's breakdown products and constant consumption of products containing the sweetener increases its concentration in blood and brain [7]. Aspartate is the precursor for such amino acids as asparagine, glutamate and glutamine. The excess of them, particularly glutamate, leads to hyperexcitability of neurons and is one of the factors that induce death of neurons and astrocytes. Glutamate (Glu) a neurotransmitter - is present in glutamatergic synapses of all neurons in the mammalian brain. Astrocytes play a significant role in maintaining proper homeostasis of these amino acids. Glutamate and aspartate released from neurons in excess are collected by the astrocytic excitatory amino acid transporters: EAAT-1 (GLAST), EAAT-2 (GLT-1) and EAAT-3. Supersaturation of the carriers with the amino acids leads to the inability to absorb them by astrocytes. In the glial cells, glutamate is metabolized to glutamine (Gln), which can then be used by neurons for resynthesis of glutamate $[15,20,24]$. Both the uptake and release of these neurotransmitters are dependent on calcium ions. Under the influence of excess excitatory amino acids in astrocytes metabotropic glutamate receptors mGluRs group I (mGluR1 and mGluR5) may become activated and lead to the ion concentration disorders inside the cell, particularly $\mathrm{Ca}^{2+}, \mathrm{Na}^{+}$and $\mathrm{K}^{+}$. The increase in intracellular calcium levels leads to the release of substantial quantities of glutamate. Alpha glutamate released from astrocytes activates NR2B subunit of presynaptic and postsynaptic $\mathrm{N}$-methyl-D-aspartate receptors (NMDA) and presynaptic $m G$ luRs receptors, leading to hyperexcitability of neurons. As a result, the increased firing causes the death of neurons by excessive action of Glu on NMDA receptors [13].

This phenomenon is called excitotoxicity and the amino acids, aspartic acid and glutamic acid, present in excess are called excitotoxins. The action of these neurotransmitters causes subsequent reactions. Proper enzymatic processes in the neurons are then affected. Aspartic acid as a metabolite of consumed aspartame has the ability to bind neuronal NMDA receptors. As a result of continuous stimulation of nerve cells, intracellular ATP stores become depleted and physiological responses are then affected. This leads to alterations in the uptake of calcium ions. Consequently, it leads to mitochondrial damage in the cell and energetic disorders. Then the cell membrane is damaged and the reactive oxygen species (ROS) are released causing oxidative stress and further degeneration of nerve cells and glia (Fig. 2). The capillary permeability is increased and the destruction of the CNS cells is continued [3].

Studies have shown that after 2 weeks of a permanent consumption, aspartame in the acceptable concentration of $40 \mathrm{mg} / \mathrm{kg}$ significantly increases the levels of nitric oxide (NO) in the brain [19]. Excessive stimulation of glutamate receptors causes the production and accumulation of reactive nitrogen, which leads to the formation of free radicals including nitric peroxide. Both reactive species of nitrogen and oxygen formed by the action of excitatory amino acids contribute to many cell-killing reactions in CNS. They damage proteins, DNA and particularly mitochondrial DNA in the cells $[2,19]$.

On the one hand, astrocytes have a protective effect during glutamate-induced neuronal death. On the other hand, the accumulation of Glu in excess in the intercellular space results in the activation of astrocytes and intensification of this amino acid neurotoxicity. The activated glia produce neurotoxic substances such as cytokines and nitric oxide. Upon the death of neurons caused by excitotoxicity of glutamate and aspartate, the activation of microglia occurs resulting in the production of toxic substances $\left(\mathrm{NO}, \mathrm{O}_{2}\right)$ and pro-inflammatory cytokines inter alia IL-1, IL-6, TNF- $\alpha, \mathrm{PGE}_{2}[13,31]$.

In summary, a metabolite of aspartame - aspartate - affects the excess of glutamate in the CNS and both of these amino acids are excitotoxins for neurons and astrocytes. As described above, alterations in neurons and astrocytes are similar to those occurring in neurodegenerative diseases such as Alzheimer's disease, epilepsy, Huntington's disease and multiple sclerosis $[15,31]$.

\section{Methanol's slight influence on brain structures}

Another product produced by the metabolism of aspartame is methanol which constitutes $10 \%$ of the breakdown products of the sweetener. After consumption of aspartame methanol is converted to formaldehyde and then to formic acid. Initially, methyl alcohol, which is weaker than ethanol, affects the depression of the central nervous system. This is the latency period after which blurred vision and even blindness occur 


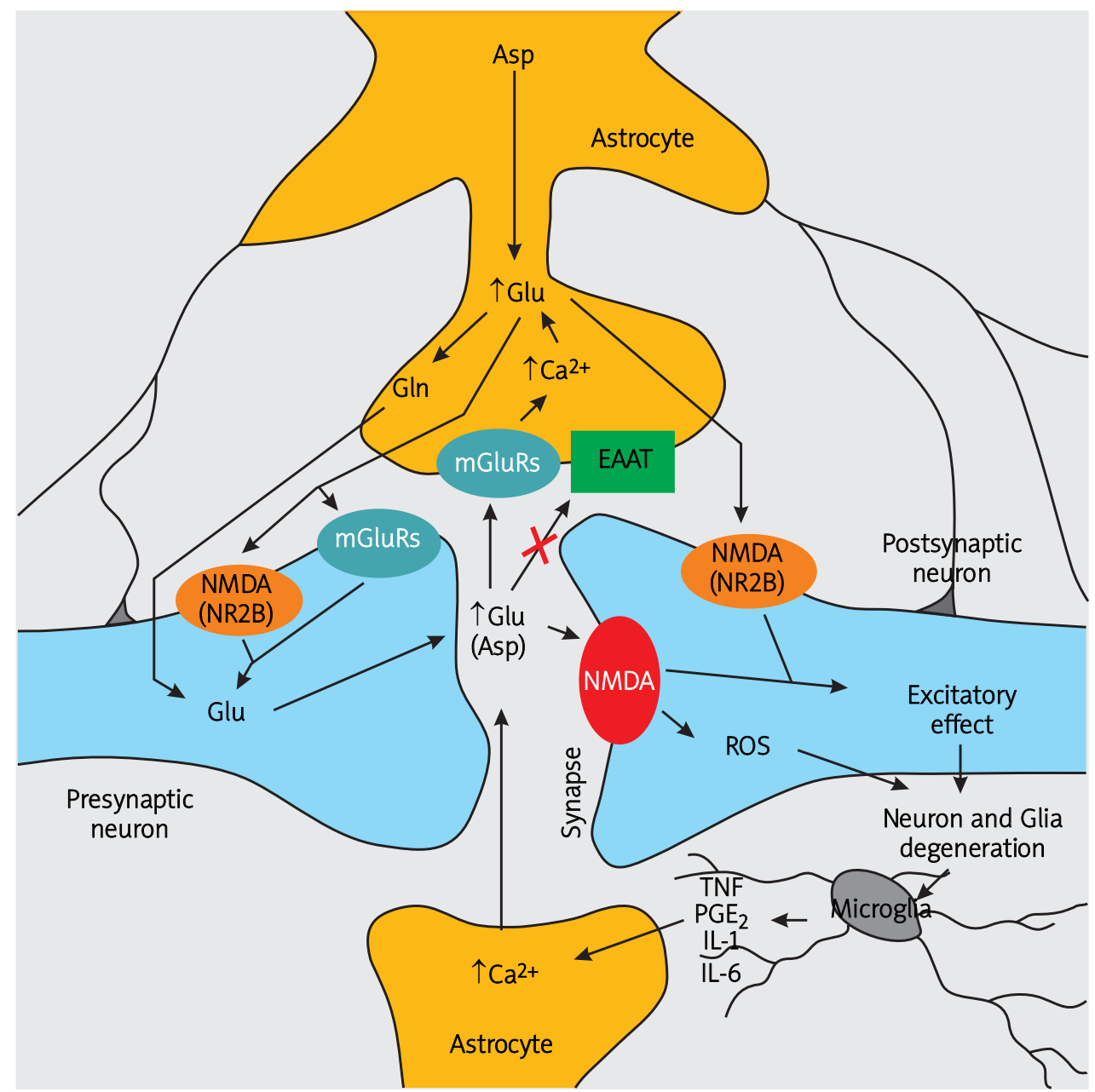

Fig. 2. Aspartate (Asp) transported by EAAT carriers in excess causes excitotoxicity by acting on NMDA receptors. It also contributes to the formation of excess glutamate (Glu). In astrocytes, Glu after conversion to glutamine (GIn), is resynthesized in neurons. Glu released from astrocytes influences the NMDA receptors containing NR2B subunit in the pre- and postsynaptic membrane and glutamate receptors mGluRs in the presynaptic membrane. As a result, Glu is released to the synaptic space in large quantities and the ability of astrocytes to uptake the neurotransmitter by EAAT carriers is reduced. mGluRs receptors are stimulated in the membrane of astrocytes. This increases the release of $\mathrm{Ca}^{2+}$ in glial cells which further affects the exocytosis of Glu from astrocytes into the synaptic space. Glu acting on NMDA receptors present in the postsynaptic membrane, leads to excitotoxicity, free radicals formation (ROS) and neurons and glia degeneration. Degenerative changes activate also microglia, which releases the factors such as TNF, PGE2, IL-1, IL-6, which increase the concentration of $\mathrm{Ca}^{2}+$ in astrocytes and intensify Glu exocytosis.

under the influence of the transformation of methanol to formaldehyde in the retina. As a result of the accumulation of formate, metabolic acidosis occurs and this may eventually cause CNS depression, coma and death from respiratory system paralysis. Methanol poisoning can occur after consumption of chilled beverages containing aspartame after physical exertion or after losing a large amount of fluid under the influence of high air temperature $[5,7,18]$.
Butchko et al. in his review paper concluded "The safety of methanol and methanol derived from aspartame has been extensively evaluated. Based on metabolism studies, it is not possible for a human to ever consume enough aspartame in products to raise blood formate concentrations. Because formate is the toxic metabolite of methanol, the lack of formate accumulation after very large doses of aspartame indicates that the conversion of aspartame to methanol is not suf- 
ficient to induce any toxicity from methanol or its metabolites" [5].

\section{Diketopiperazine - aspartame metabolite formed as a result of prolonged storage of food products}

It has been suggested recently that the derivative of aspartame: diketopiperazine (DKP) is a major carcinogenic factor [29]. It arises as a result of prolonged storage of products containing the sweetener in high temperature and $\mathrm{pH}$ above 6 . Studies on aspartamesweetened beverages in the Polish market showed the highest concentrations of phenylalanine and diketopiperazine in energy drinks and cola [27]. The European Food Safety Authority established the DKP acceptable daily intake of $7.5 \mathrm{mg} / \mathrm{kg}$ b.w./day [8].

One major cause of perennial speculation about the safety of aspartame was its carcinogenic effect on the brain. The debate on carcinogenicity of the sweetener started in the 1980s after approval of aspartame by the Food and Drug Administration (FDA) as an acceptable food product. On the strength of studies conducted by the FDA, Onley et al. concluded that aspartame may be a carcinogen [5]. Researches on Sprague-Dawley's rats revealed the presence of minor amounts of brain tumours originating mainly from the glial tissue, including the astrocytes. They were gliomas: astrocytomas, oligodendrogliomas and also medulloblastomas and meningiomas. The FDA commissioner denied this speculation and officially stated that aspartame is not carcinogenic. In 1996, Onley et al. presented further arguments in favour of the fact that the artificial sweetener can cause cancer [22]. Their assertion was based on the data from the U.S. Surveillance, Epidemiology and End Results (SEER) Program, supported by the National Cancer Institute (NCl). They noticed that the incidence of brain tumours has increased with the appearance of aspartame on the market. Moreover, based on the findings of Shepard et al., they assumed that the cause of the brain tumours is the nitrosated aspartame [22]. Both the FDA and $\mathrm{NCl}$, as well as other entities such as the United Kingdom Department of Health, the Scientific Committee on Food of the European Union and the Australia/New Zealand Food Authority (ANZFA) have not confirmed Onley's fears and accepted aspartame as a sweetener suitable for consumption [5,22]. Probably aspartame has no cancerogenic effect on the structure of the brain in children [12].
Some sources suggest that the possible pathogenesis of the brain tumours arising as a result of the artificial sweetener is the direct and indirect activation of oncogenes that increase the risk of uncontrolled cell division [25]. Another reason may be a lack of glucose in the CNS caused by the consumption of dietetic foods. The brain is sensitive to glucose deficiency [25].

In 2006, Soffritti et al.'s results appeared indicating a significant carcinogenic effect of aspartame. They indicate that aspartame is a carcinogenic agent, even at a much lower dose $(20 \mathrm{mg} / \mathrm{kg})$ than the acceptable daily intake (40 mg/kg) [29]. The main source of brain tumours caused by the artificial sweetener are astrocytes, hence the highest percentage of tumours are gliomas. Moreover, medulloblastomas and meningiomas were observed. Diketopiperazine derived from aspartame may cause cancer in various tissues and mammals' organs. The highest proportion of cancers were lymphomas occurring mainly in the lungs and lymph nodes and peripheral leukemias. Moreover, the histiocytic sarcomas of the lungs, liver, spleen and nodes were shown. A large number of malignancies derived from the renal pelvis and ureter. In the peripheral nervous system, schwannomas mainly from cranial nerves were present. Neoplastic lesions were also related to the olfactory epithelium [29]. Studies in humans show a higher incidence of glioma in people who consume aspartame [25]. However, some authors do not provide assurance that the cancer can be caused by other factors [16].

\section{Conclusions}

This article analyses the direct and indirect role of astrocytes participating in the toxic effects of metabolites of aspartame. These glial cells modulate BBB by functional changes in endothelial neutral amino acid transporters. As a result of consuming aspartame, phenylalanine shows a significant affinity for the NAAT transporters in the BBB blocking access for the essential amino acids necessary to the synthesis of dopamine and serotonin in the CNS. Astrocytes may play an indirect role in this process.

Aspartate present in excess as a metabolite of aspartame is neurotoxic and it is a substrate for glutamate. This amino acid acting on neuronal mGluR receptors and NMDA receptors leads to hyperexcitability of cells, free radicals release, oxidative stress and neuronal degeneration. Initially astrocytes are the protectors of neurons and later, with an excess of gluta- 
mate in the extracellular space, they are activated and release toxic substances intensifying neurodegeneration.

The methanol, contained in aspartame, is insufficient to bring about alterations in the CNS.

Astrocytes are the source of cancers such as astrocytoma caused by the carcinogenic effect of diketopiperazine.

Further research of aspartame's impact on the morphology and function of astrocytes and neurons is necessary to be carried out.

\section{References}

1. Barua J, Bal A. Emerging facts about aspartame. Journal of the Diabetic Association of India 1995; http://dorway.com/doctors speak-out/emerging-facts-about-aspartame/.

2. Blaylock RL Excitotoxins, Neurodegeneration \& Neurodevelopment. Dorway 2000; http://dorway.com/doctors-speak-out/dr-blaylock/excitotoxins-neurodegeneration-neurodevelopment/.

3. Bowen J, Evangelista AM. Brain cell damage from amino acid isolates: a primary concern from aspartame-based products and artificial sweetening agents. World Natural Health Organisation 2002; http://www.wnho.net/aspartame_brain_damage.htm.

4. Brookes N. Neutral amino acid transport in astrocytes: characterisation of $\mathrm{Na}^{+}$-dependent and $\mathrm{Na}^{+}$-independent components of $\alpha$-aminoisobutyric acid uptake. J Neurochem 1988; 51: 19131918.

5. Butchko HH, Stargel WW, Comer CP, Mayhew DA, Benninger C, Blackburn GL, de Sonneville LMJ, Geha RS, Hertelendy Z, Koestner A, Leon AS, Liepa GU, McMartin KE, Mendenhall CL, Munro IC, Novotny EJ, Renwick AG, Schiffman SS, Schomer DL, Shaywitz BA, Spiers PA, Tephly TR, Thomas JA, Trefz FK. Aspartame: review of safety. Reg Toxicol Pharmacol 2002; 35: S1-S93.

6. Daubert EA, Condron BG. Serotonin: a regulator of neuronal morphology and circuitry. Trends Neurosci 2010; 33: 424-434.

7. Ekong MB. Aspartame: Sweet or Bitter. The Internet Journal of Health 2009; 9: 2.

8. European Commision, Health and Consumer Protection Direc torate-General. Opinion of the Scientific Commitee on Food: Update on the Safety of Aspartame. European Commition on Food 2002; ec.europa.eu/food/fs/sc/scf/out155_en.pdf.

9. Evangelista AM. History of aspartame. World Natural Health Organisation 2004; http://www.wnho.net/history_of_aspartame.htm.

10. Ferrazzoli AE. Vesicular packaging of serotonin by astrocytes. Cen tral Connecticut State University Theses, Dissertations \& Select Projects 2007; http://content.library.ccsu.edu/cdm4/item viewer.php?CISOROOT=/ccsutheses $\&$ CISOPTR $=1172 \&$ CISOBOX $=1 \&$ $\mathrm{REC}=3$.

11. Gaspar P, Cases O, Maroteaux L. The developmental role of serotonin: news from mouse molecular genetics. Nat Rev Neurosci 2003; 4: 1002-1012

12. Gurney JG, Pogoda JM, Holly EA, Hecht SS, Preston-Martin S. Asparteme consumption in relation to childhood brain tumor risk: results from a case-control study. JNCI 1997; 89: 1072-1074.
13. Hamilton MB, Attwel D. Do astrocytes really exocytose neurotransmitters? Nat Rev Neurosci 2010; 11: 227-238.

14. Hawkins RA, O'Kane RL, Simpson IA, Vina JR. Structure of the bloodbrain barrier and its role in the transport of amino acids. J Nutr 2006; 136: 218S-226S.

15. Humphries P, Pretorius E, Naude H. Direct and indirect cellular effects of aspartame on the brain. Eur J Clin Nutr 2008; 62: 451462.

16. Lim U, Subar AF, Mouw T, Hartge P, Morton LM, Stolzenberg-Solomon R, Campbell D, Hollenbeck AR, Schatzkin A. Consumption of Aspartam-Containing Beverages and Incidence of Hematopoietic and Brain Malignancies. Cancer Epidemiol Biomarkers Prev 2006; 15: 1654-1659.

17. Magnuson BA, Burdock GA, Doull J, Kroes RM, Marsh GM, Pariza MW, Spencer PS, Waddell WJ, Walker R, Williams GM. Aspartame: a safety evaluation based on current use levels, regulations and toxicological and epidemiological studies. Crit Rev Toxicol 2007; 37: 629-727.

18. Monte WC. Aspartame, Methanol \& the Public Health. J Appl Nutr 1984; 36: 42-54.

19. Mourad IM, Noor NA. Aspartame (a widely used artificial sweetener) and oxidative stress in the rat cerebral cortex. Int J Pharm Biomed Sci 2011; 2: 4-10.

20. Nedergaard M, Ransom B, Goldman AS. New roles for astrocytes: redefining the functional architecture of the brain. Trends Neurosci 2003; 26: 523-530.

21. Nelson DL, Cox MM. Lehninger Principles of Biochemistry. $5^{\text {th }}$ ed. W. H. Freeman and Company, New York 2008.

22. Olney JW, Farber NB, Spitznagel E, Robins LN. Increasing brain tumor rates: is there a link to aspartame? J Neuropathol Exp Neurol 1996; 55: 1115-1123.

23. Omidi Y, Barar J, Ahmadian S, Heidari HR, Gumbleton M. Characterisation and astrocitic modulation of system $L$ transporters in brain microvasculature endothelial cells. Cell Biochem Funct 2008; 26: 381-391.

24. Pinheiro PS, Mulle C. Presynaptic glutamate receptors: physiological functions and mechanisms of action. Nat Rev Neurosci 2008; 9 : 423-436.

25. Roberts HJ. Does Aspartame Cause Human Brain Cancer? J Adv Med 1991; 4: 231-241.

26. Rowe RC, Sheskey PJ, Quinn ME. Handbook of Pharmaceutical Excipients. $6^{\text {th }}$ ed. Pharmaceutical Press and American Pharmacists Association, London 2009.

27. Rój A, Stasiuk E. Oznaczenia jakościowe w zakresie zawartości aspartamu i jego metabolitów w napojach gazowanych bezalkoholowych z zastosowaniem techniki HPLC. Bromat Chem Toksykol 2009; 3: 543-547.

28. Sękalska B. Zawartość sztucznych substancji słodzących - aspartamu, acesulfamu K i sacharynianu sodu w napojach dietetycznych. Żywn Nauka Technol Jakość 2007; 3: 127-138.

29. Soffritti M, Belpoggi F, Esposti DD, Lambertini L, Tibaldi E, Rigano A. First Experimental Demonstration of the Multipotential Cancerogenic Effects of Aspartame Administrated in the Feed to Sprague-Dawley Rats. Environ Health Perspect 2006; 114: 379-385. 
30. Stegink LD, Wolf-Novak LC, Filer LJ Jr, Bell EF, Ziegler EE, Krause WL, Brummel MC. Aspartame-sweetened beverage: effect on plasma amino acid concentrations in normal adults and adults heterozygous for phenylketonuria. J Nutr 1987; 117: 1989-1995.

31. Szydłowska K, Kamińska B. Farmakologiczna modulacja funkcji i żywotności astrocytów - jako nowa strategia neuroprotekcji po niedokrwieniu. Kosmos 2008; 57: 315-329.

32. Zhou Q, Palmiter RD. Dopamine-deficient mice are severely hypoactive, adipsic and aphagic. Cell 1995; 83: 1197-1209. 